\title{
Sistem Rekomendasi Wisata Pantai menggunakan Metode Simple Additive Weighting
}

\author{
Suherman Suherman a,1,*, Sunny Samsuni a,2 dan Imam Lukman Hakim ${ }^{\mathrm{a}, 3}$ \\ ${ }^{a}$ Universitas Serang Raya, Jl. Serang Raya KM.5 (Taman Drangong) Serang Banten, Indonesia. \\ ${ }^{1}$ suherman.unsera@gmail.com; ${ }^{2}$ sunnysamsuni@unsera.ac.id; ${ }^{3}$ imamluqman.it@gmail.com \\ * corresponding author
}

\begin{abstract}
INFORMASI ARTIKEL ABSTRAK
Dikirim: 12 November 2019

Diulas: 21 November 2019

Direvisi: 28 Februari 2020

Diterbitkan: 27 April 2020

Kata Kunci:

Pantai Anyer

Wisata

Wisatawan

Simple Additive Weighting

Banyaknya wisata pantai yang ada di Kabupaten Serang atau wilayah pantai Anyer dan beragamnya keinginan setiap wisatawan, maka wisatawan diperlukan pengetahuan berwisata dalam hal memilih lokasi wisata yang diinginkan. Bagi wisatawan yang telah memiliki pengalaman berwisata di pantai Anyer, maka tidak terlalu sulit untuk menentukan lokasi wisata yang diinginkan, namun sebagian besar wisatawan yang belum memiliki pengalaman wisata di pantai Anyer maka akan memiliki kesulitan untuk dapat menentukan lokasi wisata pantai yang diharapkan. Penelitian ini bertujuan untuk memberikan rekomendasi 24 tempat wisata pantai Anyer kepada wisatawan. Rekomendasi yang dihasilkan menggunakan metode Simple Additive Weighting (SAW) dengan menggunakan 12 kriteria. Hasil dari penelitian ini adalah berupa aplikasi yang dapat diakses secara online. Aplikasi dapat menghasilkan rekomendasi yang tepat bagi wisatawan berupa alternatif wisata pantai beserta rinciannya seperti nama wisata pantai, alamat, titik koordinat Google Maps, foto - foto keadaan wisata pantai dan harga tiket masuk.
\end{abstract}

\section{Keywords:}

Anyer Beach

Tour

Traveler

Simple Additive Weighting

\section{ABSTRACT}

The number of beach tourism in the Serang Regency or Anyer beach region and the diversity of the desires of every tourist, then tourists are required knowledge of traveling in terms of choosing the desired tourist location. For tourists who already have the experience of traveling on the Anyer beach, it is not too difficult to determine the desired tourist location, but most tourists who do not have the tourist experience on the Anyer beach will have difficulty being able to determine the expected beach tourism location. This study aims to provide recommendations of 24 Anyer beach tourist attractions to tourists. Recommendations generated using the Simple Additive Weighting (SAW) method using 12 criteria. The results of this study are in the form of applications that can be accessed online. The application can produce appropriate recommendations for tourists in the form of alternative beach tourism along with details such as the name of the beach tour, address, coordinates of Google Maps, photos of the state of beach tourism and the price of admission.

This is an open access article under the CC-BY-SA license.

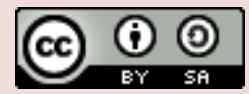

\section{Pendahuluan}

Banten merupakan sebuah wilayah propinsi yang terletak di ujung barat Pulau Jawa dan pernah menjadi bagian dari Propinsi Jawa Barat banyak memiliki pantai-pantai yang indah dan mempesona. Diantaranya yaitu Pantai Sawarna yang indah bagaikan surga, Pantai Anyer yang eksotis atau Pantai Karang Taraje yang menakjubkan. Wilayah yang berhadapan langsung dengan Samudera Hindia ini serta lokasinya yang tidak terlalu jauh dari Daerah Khusus Ibukota (DKI) Jakarta membuat pantai-pantai di Banten banyak dikunjungi wisatawan setiap akhir pekannya. Menurut Peraturan Daerah (PERDA) Kabupaten Serang Nomor 
dua Tahun 2013 [1] tentang Rencana Zonasi Wilayah Pesisir dan Pulau-Pulau Kecil Kabupaten Serang Tahun 2013 - 2033 Pasal 43 ayat 2 bahwasanya pariwisata pantai Kabupaten Serang memiliki luas wilayah kurang lebih 2375.6 ha (kurang lebih dua ribu tiga ratus tujuh puluh lima koma enam hektar). Tabel 1 merupakan tabel data jumlah kunjungan wisatawan nusantara dan mancanegara kabupaten Serang tahun 2017 terhadap obyek wisata alam/buatan/pantai [2].

Tabel 1. Daftar jumlah kunjungan wisatawan tahun 2017

\begin{tabular}{clcc}
\hline \multirow{2}{*}{ Bo } & Bulan & \multicolumn{2}{c}{ Asal Wisatawan } \\
\cline { 3 - 4 } & & $\begin{array}{c}\text { Nusantara (lokasl) } \\
\text { (orang) }\end{array}$ & $\begin{array}{c}\text { Mancanegara } \\
\text { (orang) }\end{array}$ \\
\hline 1 & Januari & 567.896 & 10 \\
\hline 2 & Februari & 298.786 & 8 \\
\hline 3 & Maret & 344.576 & - \\
\hline 4 & April & 365.788 & 6 \\
\hline 5 & Mei & 245.944 & 42 \\
\hline 6 & Juni & 1.561 .044 & 112 \\
\hline 7 & Juli & 954,743 & 240 \\
\hline 8 & Agustus & 454.253 & 165 \\
\hline 9 & September & 1.854 .889 & 103 \\
\hline 10 & Oktober & 211.097 & 143 \\
\hline 11 & November & 463.378 & 977 \\
\hline 12 & Desember & 1.845 .365 & 140 \\
\hline & Jumlah & 9.167 .759 & \\
\hline
\end{tabular}

Sumber : Dinas Pemuda, Olahraga dan Pariwisata Kabupaten Serang, 2017

Setiap wisatawan memiliki perbedaan dan kebutuhan yang unik terhadap tempat wisata seperti faktor komitmen terhadap keluarga, tingkat pendapatan, kepribadian wisatawan, transportasi dan akses jalan, serta insfrastruktur fasilitas pendukung akomodasi [3]. Pengembangan objek wisata diperlukan adanya fasilitas yang lengkap agar dapat memenuhi kebutuhan pengunjung [4]. Dalam memenuhi kebutuhan pengunjung terdapat faktor yang harus diperhatikan oleh wisatawan dalam rangka merencanakan wisatanya membuat tantangan tersendiri bagi pengelola pantai. Diantara keinginan para wisatawan yaitu fasilitas penginapan merupakan salah satu tempat yang dibutuhkan sebagai fasilitas istirahat setelah melakukan perjalanan wisata. Hal ini dapat membantu pengunjung dalam memilh penginapan sesuai dengan kriteria yang diinginkan [5].

Dengan banyaknya wisata pantai yang ada di Kabupaten Serang atau wilayah pantai Anyer dan beragamnya keinginan setiap wisatawan, maka wisatawan diperlukan pengetahuan berwisata dalam hal memilih lokasi wisata yang diinginkan. Bagi wisatawan yang telah memiliki pengalaman berwisata pantai di pantai Anyer, maka tidak terlalu sulit untuk menentukan lokasi wisata yang diinginkan[6], namun sebagian besar wisatawan yang belum memiliki pengalaman wisata di pantai Anyer maka akan memiliki kesulitan untuk dapat menentukan lokasi wisata pantai yang diharapkan, kecuali wisatawan tersebut memasuki lokasi pantai satu per satu untuk melihat lokasi pantai yang diinginkan[7], namun hal tersebut menjadi masalah bagi wisatawan, yaitu kemacetan, biaya, waktu dan tenaga.

Lemahnya pengalaman dan pengetahuan wisatawan dalam merencanakan wisatanya akan menjadi permasalahan terhadap tingkat kepuasan yang akan dirasakan setelah melakukan wisata [8]. Untuk mendukung perkembangan dengan meningkatnya pembangunan dan kemersialisasi tempat wisata pantai yang up to date serta membantu wisatawan dalam menentukan lokasi wisata yang diinginkan, maka pengembangan system informasi sangat diperlukan[9] bagi Dinas Pariwisata di Propinsi Banten dalam mendukung perjalanan wisatawan sebelum berwisata yaitu mencari informasi tentang wisata yang akan dikunjungi, kemudian membandingkannya dan memilih tempat wisata yang sesuai dengan kriteria [4].

Penelitian ini untuk memberikan kemudahan bagi wisatawan dalam menentukan 24 lokasi wisata yang diinginkan di Pantai Anyer, dengan menggunakan 12 kriteria yang dibutuhkan oleh wisatawan[10], yaitu pantai yang berkarang atau tidak, pantai yang memiliki mushola atau sarana ibadah, memiliki toilet, dekat dengan penginapan, dekat dengan tempat kuliner, pantai luas (jarak pantai dan tepi pantai jauh), laut landai, pantai yang rindang, tersedia tempat peristirahatan(saung), dekat dengan fasilitas kesehatan, fasilitas bermain air dan tersedianya tempat atau lahan parkir yang luas agar wisatawan dapat menyesuaikan dengan kendaraan yang akan mereka gunakan untuk berwisata [11]. Dalam memilih kriteria metode yang digunakan adalah Simple Additive Weighting, dengan memberikan pilihan - pilihan kriteria wisata pantai yang wisatawan inginkan. Kelebihan dari metode Simple Additive Weighting (SAW) dibanding dengan model pengambil keputusan lainnya terletak pada kemampuannya untuk melakukan penilaian secara lebih tepat[12] karena didasarkan pada nilai kriteria dan bobot preferensi yang sudah ditentukan, selain itu SAW juga dapat menyeleksi alternatif terbaik dari sejumlah alternatif yang ada karena adanya proses perangkingan setelah menentukan bobot untuk setiap atribut [13]. Penelitian ini melengkapi penelitan lain dimana belum pernah 
dilakukan penelitian preferensi wisata pantai di wilayah Banten dengan metode SAW. menggunakan metode Simple Additive Weighting (SAW) dengan menggunakan 12 kriteria yang terdiri dari pantai tidak berkarang, pantai yang memiliki sarana ibadah, memiliki toilet, dekat dengan penginapan, dekat dengan tempat kuliner, pantai luas (jarak pantai dan tepi pantai jauh), laut landai, pantai yang rindang, tersedia tempat peristirahatan(saung), dekat dengan fasilitas kesehatan, fasilitas bermain air dan tersedia lahan parkir yang luas.

\section{Metode}

berikut[14]:

Penelitian ini menggunakan Metode Simple Additive Weighting dengan lengkah-langkah sebagai

1. Menentukan kriteria - kriteria yang akan dijadikan acuan dalam pengambilan keputusan, yaitu $\mathrm{C}_{\mathrm{j}}$

2. Memberikan nilai setiap alternatif $A_{i}$ pada setiap kriteria $C_{j}$ yang sudah ditentukan, dimana nilai tersebut diperoleh berdasarkan nilai crisp; $\mathrm{i}=1,2, . . \mathrm{m}$ dan $\mathrm{j}=1,2, \ldots \mathrm{n}$.

3. Menentukan rating kecocokan setiap alternatif untuk kriteria kemudian memodelkannya ke dalam bilangan.

4. Memberikan nilai bobot (W) berdasarkan tingkat kepentingan.

5. Menentukan normalisasi matriks dengan cara menghitung suatu nilai dari suatu rating kinerja ternormalisasi $\mathrm{r}_{\mathrm{ij}}$ dan untuk alternatif $\mathrm{A}_{\mathrm{i}}$ dalam atribut $\mathrm{C}_{\mathrm{j}}$ berdasarkan persamaan yang disesuaikan dengan jenis atribut.

6. Melakukan proses perangkingan dengan cara mengalikan matriks ternormalisasi (R) dengan nilai bobot (W).

7. Menentukan nilai suatu preferensi untuk dapat mengetahui setiap alternatif $\left(\mathrm{V}_{\mathrm{i}}\right)$ yaitu dengan cara menjumlahkan hasil kali antara matriks ternormalisasi (R) dengan suatu nilai bobot (W).

8. Nilai $\mathrm{V}_{\mathrm{i}}$ yang lebih besar akan mengidentifikasikan bahwa alternatif $\mathrm{A}_{\mathrm{i}}$ lebih terpilih.

Dengan menggunakan langkah 1,2,3 maka dapatlah ditentukan Alternatif dan Kriteria yang ditunjukkan pada Tabel 2 dan Tabel 3.

Tabel 2. Daftar alternatif wisata pantai

\begin{tabular}{ccl}
\hline No & $\begin{array}{c}\text { Kode } \\
\text { Kriteria }\end{array}$ & \multicolumn{1}{c}{ Nama Kriteria Wisata Pantai } \\
\hline 1 & A1 & Pantai Anyer \\
\hline 2 & A2 & Pantai Anyer II \\
\hline 3 & A3 & Pantai 0 KM (Mercusuar) \\
\hline 4 & A4 & Pantai Pal Anyer \\
\hline 5 & A5 & Pantai Pasir Putih 234 Anyer \\
\hline 6 & A6 & Pantai Pasir putih 121 Anyer \\
\hline 7 & A7 & Pantai Sambolo 2 \\
\hline 8 & A8 & Pantai Sambolo 1 \\
\hline 9 & A9 & Pantai Bandulu \\
\hline 10 & A10 & Pantai Pasir Putih Sirih \\
\hline 11 & A11 & Pantai Saung Cibeureum \\
\hline 12 & A12 & Pantai Palem Cibeureum \\
\hline
\end{tabular}

\begin{tabular}{lll} 
No & Kode Kriteria & \multicolumn{1}{c}{ Nama Kriteria Wisata Pantai } \\
\hline 13 & A13 & Pantai Kelapa Gading \\
\hline 14 & A14 & Pantai Florida Indah \\
\hline 15 & A15 & Pantai Pasir Putih Anyer \\
\hline 16 & A16 & Pantai Legon Prima \\
\hline 17 & A17 & Pantai Pasir Putih Tawing \\
\hline 18 & A18 & Pantai Karang Bolong \\
\hline 19 & A19 & Pantai Muara Cipacung \\
\hline 20 & A20 & Pantai Baraya \\
\hline 21 & A21 & Pantai Jambu \\
\hline 22 & A22 & Pantai Wara Wiri \\
\hline 24 & A23 & Pantai Karang Kitri \\
\hline
\end{tabular}

Tabel 3. Daftar kriteria pantai

\begin{tabular}{ccl}
\hline No & $\begin{array}{c}\text { Kode } \\
\text { Kriteria }\end{array}$ & \multicolumn{1}{c}{ Kriteria Wisata Pantai } \\
\hline 1 & C1 & Pantai yang tidak berkarang \\
\hline 2 & C2 & Terdapat sarana ibadah \\
\hline 3 & C3 & Terdapat Toilet \\
\hline 4 & C4 & Dekat dengan penginapan \\
\hline 5 & C5 & Dekat dengan fasilitas kesehatan \\
\hline 6 & C6 & Dekat dengan tempat kuliner \\
\hline 7 & C7 & Jarak tepi pantai jauh \\
\hline 8 & C8 & Laut landai \\
\hline 9 & C9 & $\begin{array}{l}\text { Terdapat tempat peristirahatan } \\
\text { (saung) }\end{array}$ \\
\hline 10 & C10 & Fasilitas bermain air \\
\hline 11 & C11 & Area yang luas \\
\hline 12 & C12 & Pantai yang rindang \\
\hline
\end{tabular}

Tabel 4. Tabel bobot kriteria

\begin{tabular}{clc}
\hline No & \multicolumn{1}{c}{ Kriteria } & Bobot \\
\hline 1 & Berkarang/tidak & $9 \%$ \\
\hline 2 & Terdapat sarana ibadah & $9 \%$ \\
\hline 3 & Fasilitas toilet & $15 \%$ \\
\hline 4 & Dekat dengan penginapan & $6 \%$ \\
\hline 5 & Dekat dengan fasilitas kesehatan & $5 \%$ \\
\hline 6 & Dekat dengan tempat kuliner & $9 \%$ \\
\hline 7 & Jarak tepi pantai jauh & $5 \%$ \\
\hline 8 & Laut landai & $5 \%$ \\
\hline 9 & Tempat perisitirahatan (saung) & $10 \%$ \\
\hline 10 & Fasilitas bermain air & $8 \%$ \\
\hline 11 & Area yang luas & $10 \%$ \\
\hline 12 & Pantai yang rindang/sejuk & $9 \%$ \\
\hline
\end{tabular}

Pada Tabel 4 bobot kriteria terdapat 12 variabel yang dijadikan kriteria dengan bobot tiap - tiap kriteria. Kriteria tersebut akan dibagi menjadi beberapa sub kriteria. Setiap sub kriteria mempunyai nilai sendiri yang bertujuan untuk menghasilkan pada variabel tersebut. Adapun nilai atau bobot pada sub kriteria diperlihatkan pada Tabel 5 . 
Tabel 5. Tabel bobot sub kriteria

\begin{tabular}{|c|c|c|c|}
\hline No & Kriteria & $\begin{array}{c}\text { Sub kriteria } \\
\text { (fasilitas) }\end{array}$ & Nilai /bobot \\
\hline \multirow{2}{*}{1} & \multirow{2}{*}{ Pantai yang tidak berkarang } & $\mathrm{Ya}$ & 1 \\
\hline & & Tidak & 0 \\
\hline \multirow{2}{*}{2} & \multirow{2}{*}{ Terdapat sarana ibadah } & Ada & 1 \\
\hline & & Tidak ada & 0 \\
\hline \multirow{2}{*}{3} & \multirow{2}{*}{ Fasilitas toilet } & Ada & 1 \\
\hline & & Tidak ada & 0 \\
\hline \multirow{2}{*}{4} & \multirow{2}{*}{ Dekat dengan penginapan } & Dekat & 1 \\
\hline & & Jauh & 0 \\
\hline \multirow{2}{*}{5} & \multirow{2}{*}{ Dekat dengan fasilitas kesehatan } & Dekat & 1 \\
\hline & & Jauh & 0 \\
\hline \multirow{2}{*}{6} & \multirow{2}{*}{ Dekat dengan tempat kuliner } & Dekat & 1 \\
\hline & & Jauh & 0 \\
\hline \multirow{2}{*}{7} & \multirow{2}{*}{ Jarak tepi pantai jauh } & Jauh & 1 \\
\hline & & Dekat & 0 \\
\hline \multirow{2}{*}{8} & \multirow{2}{*}{ Laut landai } & Ya & 1 \\
\hline & & Tidak & 0 \\
\hline \multirow{2}{*}{9} & \multirow{2}{*}{ Terdapat tempat peristirahatan (saung) } & Ada & 1 \\
\hline & & Tidak ada & 0 \\
\hline \multirow{2}{*}{10} & \multirow{2}{*}{ Fasilitas bermain air } & Ada & 1 \\
\hline & & Tidak ada & 0 \\
\hline \multirow{2}{*}{11} & \multirow{2}{*}{ Area yang luas } & Luas & 1 \\
\hline & & Kurang luas & 0 \\
\hline \multirow{2}{*}{12} & \multirow{2}{*}{ Pantai yang rindang/sejuk } & $\mathrm{Ya}$ & 1 \\
\hline & & Tidak & 0 \\
\hline
\end{tabular}

Menghitung bobot kriteria dengan sub kriteria untuk menentukan alternatif yang nantinya akan menjadi pilihan. Data alternatif merupakan tempat wisata pantai wilayah Anyer. Adapun data sampel alternatif yang di ambil yaitu:

A18 /Alternatif 18 : Pantai Karangbolong

A23 /Alternatif 3 : Pantai 0 KM

A8 /Alternatif 8 : Pantai Sambolo I

Data alternatif akan digabungkan dengan data kriteria dan sub kriteria yang telah ditentukan. Selanjutnya, pada tahap ini akan menjelaskan rumus beserta perhitungan manual yang akan menghasilkan nilai akhir[15]. Adapun tabel nilai alternatif dapat dilihat pada Tabel 6.

Tabel 6. Nilai alternatif

\begin{tabular}{lrrrrrrrrrrrr}
\hline & \multicolumn{10}{c}{ Kriteria } \\
\cline { 2 - 13 } & C1 & C2 & C3 & C4 & C5 & C6 & C7 & C8 & C9 & C10 & C11 & C12 \\
\hline A18 & 0 & 1 & 1 & 0 & 0 & 0 & 1 & 1 & 1 & 0 & 1 & 1 \\
\hline A3 & 0 & 1 & 1 & 1 & 0 & 1 & 1 & 1 & 1 & 0 & 1 & 1 \\
\hline A8 & 1 & 1 & 1 & 1 & 0 & 1 & 1 & 1 & 1 & 1 & 1 & 0 \\
\hline
\end{tabular}

Rumus normalisasi menggunakan persamaan (1).

$$
R i i=\left(\frac{x_{i j}}{\max \left[x_{i j}\right]}\right)
$$

Keterangan

$\mathrm{R}_{\mathrm{ij}} / \mathrm{A} \quad$ : alternatif

$\mathrm{X}_{\mathrm{ij}} / \mathrm{n} \quad$ : nilai alternatif (diambil dari sub kriteria)

Cara menentukan matriks normalisasi yaitu dengan menggunakan persamaan (1) yaitu membagi nilai alternatif yang mempunyai nilai terbesar pada kolom kriteria. Tabel 7 menunjukkan perhitungannya.

\begin{tabular}{|c|c|c|}
\hline Hasil Perhitungan-1 & Hasil Perhitungan -2 & Hasil Perhitungan-3 \\
\hline $\mathrm{R} 11=\frac{0}{\max \{0: 0: 1\}}=\frac{0}{1}=0$ & $\mathrm{R} 12=\frac{1}{\max \{1: 1: 1\}}=\frac{1}{1}=1$ & $\mathrm{R} 19=\frac{1}{\max \{1: 1: 1\}}=\frac{1}{1}=1$ \\
\hline
\end{tabular}




\begin{tabular}{|c|c|c|}
\hline Hasil Perhitungan-1 & Hasil Perhitungan -2 & Hasil Perhitungan-3 \\
\hline $\mathrm{R} 21=\frac{0}{\max \{0: 0: 1\}}=\frac{0}{1}=1$ & $\mathrm{R} 22=\frac{1}{\max \{1: 1: 1\}}=\frac{1}{1}=1$ & $\mathrm{R} 29=\frac{1}{\max \{1: 1: 1\}}=\frac{1}{1}=1$ \\
\hline $\mathrm{R} 31=\frac{1}{\max \{0: 0: 1\}}=\frac{0}{1}=1$ & $\mathrm{R} 32=\frac{1}{\max \{1: 1: 1\}}=\frac{1}{1}=1$ & $\mathrm{R} 110=\frac{0}{\max \{0: 0: 1\}}=\frac{0}{1}=0$ \\
\hline $\mathrm{R} 13=\frac{1}{\max \{1: 1: 1\}}=\frac{1}{1}=1$ & $\mathrm{R} 14=\frac{0}{\max \{0: 1: 1\}}=\frac{0}{1}=1$ & $\mathrm{R} 210=\frac{0}{\max \{0: 0: 1\}}=\frac{0}{1}=0$ \\
\hline $\mathrm{R} 23=\frac{1}{\max \{1: 1: 1\}}=\frac{1}{1}=1$ & $\mathrm{R} 24=\frac{10}{\max \{0: 1: 1\}}=\frac{0}{1}=1$ & $\mathrm{R} 39=\frac{1}{\max \{1: 1: 1\}}=\frac{1}{1}=1$ \\
\hline $\mathrm{R} 33=\frac{1}{\max \{1: 1: 1\}}=\frac{1}{1}=1$ & $\mathrm{R} 34=\frac{1}{\max \{0: 1: 1\}}=\frac{0}{1}=1$ & $\mathrm{R} 111=\frac{1}{\max \{1: 1: 1\}}=\frac{1}{1}=1$ \\
\hline $\mathrm{R} 15=\frac{0}{\max \{0: 0: 0\}}=\frac{0}{0}=$ & $\mathrm{R} 16=\frac{0}{\max \{0: 1: 1\}}=\frac{0}{1}=0$ & $\mathrm{R} 211=\frac{1}{\max \{1: 1: 1\}}=\frac{1}{1}=1$ \\
\hline $\mathrm{R} 25=\frac{0}{\max \{0: 0: 0\}}=\frac{0}{0}=$ & $\mathrm{R} 26=\frac{1}{\max \{0: 1: 1\}}=\frac{1}{1}=1$ & $\mathrm{R} 311=\frac{1}{\max \{1: 1: 1\}}=\frac{1}{1}=1$ \\
\hline $\mathrm{R} 35=\frac{0}{\max \{0: 0: 0\}}=\frac{0}{0}=$ & $\mathrm{R} 36=\frac{1}{\max \{0: 1: 1\}}=\frac{1}{1}=1$ & $\mathrm{R} 310=\frac{1}{\max \{0: 0: 1\}}$ \\
\hline $\mathrm{R} 17=\frac{1}{\max \{1: 1: 1\}}=\frac{1}{1}=1$ & $\mathrm{R} 18=\frac{1}{\max \{1: 1: 1\}}=\frac{1}{1}=1$ & $\mathrm{R} 112=\frac{1}{\max \{1: 1: 0\}}$ \\
\hline $\mathrm{R} 27=\frac{1}{\max \{1: 1: 1\}}=\frac{1}{1}=1$ & $\mathrm{R} 28=\frac{1}{\max \{1: 1: 1\}}=\frac{1}{1}=1$ & $\mathrm{R} 212=\frac{1}{\max \{1: 1: 0\}}=\frac{1}{1}=1$ \\
\hline $\mathrm{R} 37=\frac{1}{\max \{1: 1: 1\}}=\frac{1}{1}=1$ & $\mathrm{R} 38=\frac{1}{\max \{1: 1: 1\}}=\frac{1}{1}=1$ & $\mathrm{R} 312=\frac{0}{\max \{1: 1: 0\}}=\frac{0}{1}=0$ \\
\hline
\end{tabular}

Dari proses perhitungan dalam Tabel 7 maka diperoleh hasil normalisasi yang dipaparkan pada Tabel 8.

Tabel 8. Matriks Hasil Normalisasi

\begin{tabular}{lrrrrrrrrrrrr}
\hline & \multicolumn{10}{c}{ Kriteria } \\
\cline { 2 - 15 } & C1 & C2 & C3 & C4 & C5 & C6 & C7 & C8 & C9 & C10 & C11 & C12 \\
\hline A18 & 0 & 1 & 1 & 1 & 0 & 0 & 1 & 1 & 1 & 0 & 1 & 1 \\
\hline A3 & 1 & 1 & 1 & 1 & 0 & 1 & 1 & 1 & 1 & 0 & 1 & 1 \\
\hline A8 & 1 & 1 & 1 & 1 & 0 & 1 & 1 & 1 & 1 & 1 & 1 & 0 \\
\hline
\end{tabular}

Hasil normalisasi kemudian digabungkan menjadi satu bagian tampilan matriks $\mathrm{R}(3 \times 12)$

$$
\text { sebagai berikut: } R=\left[\begin{array}{llllllllllll}
0 & 1 & 1 & 1 & 0 & 0 & 1 & 1 & 1 & 0 & 1 & 1 \\
1 & 1 & 1 & 1 & 0 & 1 & 1 & 1 & 1 & 0 & 1 & 1 \\
1 & 1 & 1 & 1 & 0 & 1 & 1 & 1 & 1 & 1 & 1 & 0
\end{array}\right]
$$

Selanjutnya, menghitung perangkingan menggunakan nilai bobot yang telah ditentukan. Adapun nilai bobot yang telah ditentukan sesuai tabel 7 diatas. Rumus perangkingan ditunjukkan pada persamaan (2).

$$
V_{i}=\sum_{j=1}^{n} w_{j} r_{i j}
$$


dimana:

$\mathrm{V}_{\mathrm{i}}$ : alternatif

$\mathrm{r}_{\mathrm{ij}}$ : nilai alternatif

W : bobot kriteria

Maka hasil yang diperoleh yaitu sebagai berikut dan ditunjukkan pada Tabel 9

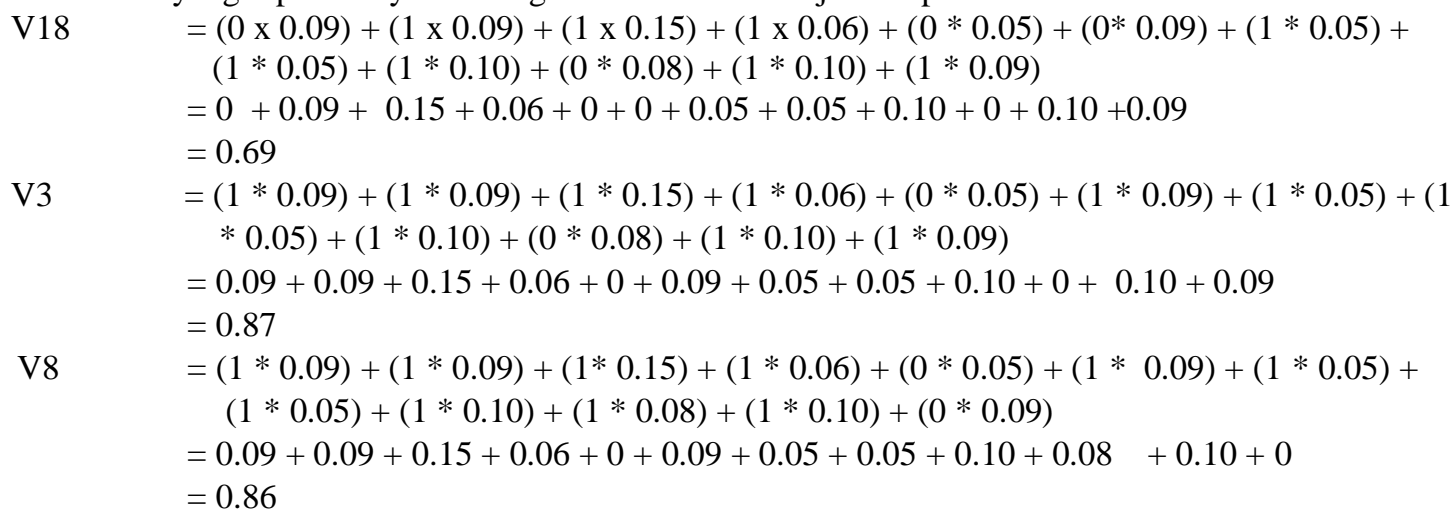

Tabel 9. Nilai Akhir (V)

\begin{tabular}{cc}
\hline Alternatif & Nilai \\
\hline V18 & 0.69 \\
\hline V3 & 0.87 \\
\hline V8 & 0.86 \\
\hline
\end{tabular}

Dengan menggunakan langkah 7 dan 8 Nilai preferensi dan alternatif.

Maka alternatif yang memiliki nilai tertinggi dan bisa dipilih menjadi rekomendasi wisata pantai dari 3 sampel yang diambil adalah : Alternatif A3 dengan nilai 0.87; Alternatif A8 dengan nilai 0.86 Alternatif A18 dengan nilai 0.69 . Tabel 10 menunjukkan perangkingan alternative.

Tabel 10. Perangkingan alternatif

\begin{tabular}{cclcc}
\hline No & Kode Alternatif & \multicolumn{1}{c}{ Nama alternatif } & Total Nilai & Perangkingan \\
\hline 1 & A3 & Pantai 0 KM & 0.87 & 1 \\
\hline 2 & A8 & Pantai Sambolo & 0.86 & 2 \\
\hline 3 & A18 & Pantai Karangbolong & 0.69 & 3 \\
\hline
\end{tabular}

\section{Hasil dan Pembahasan}

Studi kasus aplikasi rekomendasi wisata pantai ini dilakukan kepada wisatawan yang akan berwisata ke wilayah Anyer tepatnya daerah pesisir pantai. Untuk mengetahui preferensi wisatawan telah diberikan kuisioner dengan skala likert memuat enam pertanyaan yaitu (1) Apakah wisatawan membutuhkan adanya aplikasi wisata pantai untuk kemudahan informasi wisata; (2) Apakah wisatawan menyukai wisata di wilayah Anyer; (3) Apakah wisatawan memerlukan informasi tentang wisata pantai Anyer melalui jaringan yang mudah diakses (online) (4) Apakah wisatawan memerlukan informasi tentang biaya tiket masuk; (5) Apakah wisatawan membutuh informasi fasilitas yang terdapat di pantai Anyer; (6) apakah wisatawan merasa senang berwisata ke Pantai Anyer dan keadaan tempat wisata sesuai dengan yang diharapkan.

Dari hasil kuisioner dari 25 responden menunjukkan rata-rata indeks adalah $23,22 \%$ dan masih ada wisatawan yang belum mengetahui kriteria pantai yang akan mereka kunjungi bahkan beberapa dari mereka ada yang kecewa atau merasa kurang puas karena tempat wisata yang mereka kunjungi kurang sesuai dengan keinginannya. Dengan aplikasi menggunakan sistem pendukung keputusan ini permasalahan ketidakpuasan wisatawan terhadap tempat wisata yang mereka kunjungi akan bisa di minimalisir seminimal mungkin. Aplikasi dapat memberikan alternatif-alternatif sesuai dengan preferensi wisatawan.

\section{Kesimpulan dan saran}

Penelitian ini menghasilkan berupa Aplikasi berbasis online untuk rekomendasi wisatawan dalam memilih tempat wisata pantai wilayah anyer yang diinginkan. Aplikasi ini di dalamnya menggunakan metode Simple Additive Weighting (SAW) dengan menerapkan 12 alternatif dan kriteria seperti pantai tidak berkarang, pantai yang memiliki sarana ibadah, memiliki toilet, dekat dengan penginapan, dekat dengan tempat kuliner, pantai luas (jarak pantai dan tepi pantai jauh), laut landai, pantai yang rindang, tersedia tempat peristirahatan(saung), dekat dengan fasilitas kesehatan, fasilitas bermain air dan tersedia lahan parkir yang luas. 
Aplikasi ini telah diuji oleh 2 (dua) orang yang memiliki keahlian dalam bidang IT, yaitu dengan menggunakan metode blackbox untuk menguji keakuratan[16] dari aplikasi yang dihasilkan berdasarkan: aktifitas pengujian, realisasi yang diharapkan, dan hasil pengujian. Terbukti dari hasil pengujian aplikasi ini dinilai berhasil dari sisi masukan (input) dan luaran sistem (output) serta tepat dalam memberikan alternatif pilihan wisata pantai yang diinginkan, yaitu berupa nama wisatanya, alamat, titik koordinat, foto keadaan pantai dan harga tiket untuk segala kendaraan yang digunakan pengunjung. Terdapat beberapa kendala penerapan aplikasi pariwisata untuk dapat diterapkan di Indonesia yaitu masih membutuhkan kesiapan infrastruktur komunikasi yang memadai, kecakapan sumber daya manusia dalam menggunakan teknologi [17]. Hal ini tentunya dimasa yang akan datang diharapkan pemerintah Indonesia khususnya Pemeritah Provinsi Banten agar daerah wisata Pantai Anyer dapat segera mempersiapkan infrastruktur komunikasi yang baik terutama internet, pendidikan dan pelatihan dibidang kepariwisataan.

\section{Daftar Pustaka}

[1] Pemerintah Kabupaten Serang, Peraturan Daerah Kabupaten Serang No.2 Tahun 2013 Tentang Rencana Zonasi Wilayah Pesisir dan Pulau-pulau Kecil Kabupaten Serang Tahun 2013 - 2033. Serang, Indonesia, 2013.

[2] Dinas Pemuda Olah Raga dan Pariwisata Kabupaten Serang, Daftar Jumlah Kunjungan Wisatawan Nusantara dan Mancanegara. Serang: Disporapar, 2017.

[3] M. A. E. Yusendra, "Analisis Faktor-faktor yang Mempengaruhi Keputusan Pemilihan Destinasi Wisata Bagi Wisatawan Domestik Nusantara," J. Magister Manaj., vol. 01. No.1, 2015.

[4] Ikmah and A. S. Wiawati, "Sistem Pendukung Keputusan Pemilihan Tempat Wisata Purworejo," Semin. Nas. Teknol. Inf. dan Multimed. 2010, 2018.

[5] A. E. Wijaya and E. W. Utami, "Sistem Pendukung Keputusan Penilaian Penginapan di Kota Subang dengan Metode Simple Additive Weighting," STMIK Subang, vol. 2, p. 177, 2018.

[6] M. Siringo and I. M. Adikampana, "Persepsi Wisatawan Terhadap Kemacetan," Destin. Wisata, vol. 2, no. 1, 2014.

[7] B. Siregar, "Ini 5 Tips Antisipasi Kemacetan Saat Liburan," Kompas, Indonesia, p. 4, 02-Dec-2015.

[8] J. J. Spinllane, Ekonomi Pariwisata, Sejarah dan Prosesnya. Yogyakarta: Kanisius, 1985.

[9] I. Condratov, "E-Tourism : Concept And Evolution," vol. 2, no. 1, pp. 58-61, 2013.

[10] V. Middleton, Marketing in Travel and Tourism. London: Buterworth-Heinemann, 2001.

[11] R. N. Sari, R. Santoso, and H. Yasin, "Komputasi Metode SAW dan TOPSIS Menggunakan GUI Matlab Untuk Pemilihan Jenis Object Wisata Terbaik (Studi Kasus Pesona Wisata Jawa Tengah)," no. Universitas Diponegoro, 2016.

[12] M. Mathewa and S. Sahua, "Comparison of new multi-criteria decision making methods for material handling equipment selection," Manag. Sci. Lett., vol. 4, pp. 139-150, 2014.

[13] S. Kusumadewi, H. S, H. A, and Wardoyyo, Fuzzy Multi-attribute Decission Making (FUZZY MADM). Yogyakarta: Graha Ilmu, 2006.

[14] E. Turban, Decission Support System and Inteligent System, Bahasa Ind. Yogyakarta: Andi, 2005.

[15] Alireza Afshari, M. Mojahed, and R. M. Yusuf, "Simple Additive Weighting approach to Personnel Selection problem," Int. J. Innov. Manag. Technol., vol. 1, no. 5, pp. 511-515, 2010.

[16] S. Nidhra, "Black Box and White Box Testing Techniques - A Literature Review," Int. J. Embed. Syst. Appl., vol. 2, no. 2, pp. 29-50, 2012.

[17] A. S. Hussein, "The Application Of E-tourism In Small and Medium-scale Tourism In Indonesia : A Strategic Management View," J. Indones. Econ. Bus., vol. 25, no. 2, pp. 190-200, 2010. 